\title{
Ciudad, cuerpo y vida cotidiana. Materiales teóricos de una investigación en la ciudad de La Plata
}

\author{
Gabriel Armando Cachorro*
}

\begin{abstract}
Resumen: Este trabajo se enmarca en el proyecto de investigación "El campo de las prácticas corporales en la ciudad de La Plata" y propone la composición de un texto descriptivo de los términos ciudad, cuerpo y vida cotidiana, desde una perspectiva de construcción teórica estableciendo lazos con materiales empíricos recolectados en el trabajo de campo, donde se relevaron sitios de reunión social que ofrecen propuestas corporales. Los términos están relacionados entre sí, son puertas de acceso fundamentales para comprender los modos de construir la ciudadanía en la ciudad de La Plata, prestando atención a los rasgos específicos de producción del hacer social que despliegan los sujetos en sus tareas, actividades y prácticas corporales.
\end{abstract}

Palabras clave: Ciudadanía, propuestas corporales, prácticas corporales.

\section{INTRODUCCIÓN}

Este trabajo se desprende del proyecto de investigación "El campo de las prácticas corporales en la ciudad de La Plata" (CACHORRO, 2007). En el artículo se efectúa una operación de problematización de las categorías teóricas ciudad, cuerpo y vida cotidiana, con un enfoque interdisciplinario para definir sus rasgos y relaciones. Se deriva la confección de una matriz teórica disponible para ser articulada con los materiales empíricos recolectados en el trabajo de campo, donde se relevaron sitios de reunión social que ofrecen propuestas corporales. Los conceptos ciudad, cuerpo y vida cotidiana, están relacionados entre sí. Son puertas de acceso fundamentales para comprender los modos de construir la ciudadanía

\footnotetext{
"Facultad de Humanidades y Ciencias de la Educación. Universidad Nacional de la Plata, Buenos Aires, Argentina. E-mail: gcachorro@yahoo.com
} 
en la ciudad de La Plata, prestando atención a los rasgos específicos de producción del hacer social que despliegan los sujetos en sus tareas, actividades y prácticas corporales.

El artículo constituye un insumo crucial para delimitar las posiciones teóricas que explican el devenir de las prácticas corporales en la ciudad de la Plata, describir las propiedades del campo y brindar una potencia explicativa a los datos empíricos recolectados durante los relevamientos de datos en el transcurso de la investigación. Los tópicos ciudad, cuerpo y vida cotidiana, constituyen revestimientos teóricos que brindan marcos explicativos de los modos de hacer corporal de los ciudadanos, las transformaciones del espacio público, las reformulaciones de los catálogos de propuestas corporales disponibles en la ciudad de La Plata.

\subsection{CIUDAD}

La ciudad está relacionada con la idea de civilización, y se diferencia de la idea de pueblo o de ámbito rural por oposición a una cultura urbana. Una ciudad contiene los flujos de la modernidad, monta edificios, calles asfaltadas, organiza el transporte público, coloca luminarias, incluye servicios de redes de agua, luz, gas y establece impactos ambientales desde el equilibrio que debe mantener con los espacios verdes. Plantea eventuales parquizaciones. Actúa sobre la naturaleza distribuyendo árboles en forma simétrica en las avenidas, ramblas y plazas. (WILLIAMS, 2003) señala como suele oponerse la noción de ciudad a la de campo y en el derrotero histórico como tensan las relaciones entre clases sociales estableciendo distinciones entre los suburbios externos e inferiores frente al centro de la ciudad. En la ciudad se suele establecer divisiones entre el espacio público y el espacio privado. La ciudad se ofrece como un mapa que es interpretado por sus moradores capaces de marcar caprichosos surcos por sitios predilectos.

Ser ciudadano implica vivir la ciudad y adquirir un roce social, "tener calle" como expresa el sentido más vulgar del término, construyendo un anecdotario de experiencias protagonizadas en lugares visitados, sitios explorados, ámbitos conocidos. Estar 
pendiente de nuevos paisajes, apertura de centros recreativos, bares, cafés, discotecas, ferias ambulantes, recuperación de fábricas, llamadas de candombe, ciclos de arte en el teatro argentino, festivales, fiestas, recitales del día de la ciudad, exposiciones carreras de caballos, clases de gimnasia abiertas, maratones que la ciudad lleva en sus entrañas.

El sujeto poetiza la ciudad: la ha rehecho para su propio uso al deshacer las limitaciones del aparato urbano; impone al orden externo de la ciudad su ley de consumidor de espacio. El barrio es pues en el sentido estricto del término, un objeto de consumo que se apropia el usuario mediante la apropiación del espacio público. (DE CERTEAU, 1999, p. 12).

La construcción de la ciudadanía se hace estableciendo relaciones con los sitios que ofrece la ciudad. Los circuitos de los sujetos, sus paradas, los paseos entregan episodios y algunos de ellos adosan situaciones que se graban en la memoria como recuerdos imborrables. Un terreno baldío reflota imágenes del pasado con escenas de la niñez compartida con amigos, una esquina recuerda el primer beso con alguien a quien se amaba, los olores conservados intactos y los ruidos de algunos sitios también hacen volver experiencias sociales de otros tiempos. Los reencuentros con objetos extraviados y personas que hacía mucho no veíamos rebobinan situaciones compartidas en algún tramo de nuestras vidas. En esta posible proyección de la mirada es interesante la promoción de otros puntos de vista que nos habilite chances de vivenciar aspectos de la ciudad que escapan a las prácticas tristes y aburridas de sujetos moribundos o zombies que se arrastran por las calles sin percibir otras modalidades.

La ciudad no dice su pasado, lo contienen en las líneas de una mano, escrito en las esquinas de las calles, en las rejas de las ventanas, en los pasamanos de las escaleras, en las antenas de los para rayos, en las astas de las banderas, cada segmento surcado a su vez por arañazos, muescas, incisiones, comas. (CALVINO, 1999, p. 22). 
La configuración de la ciudad se monta en la confluencia de historias que son contiguas, no se tocan, pasan una al lado de la otra porque son historias simultáneas que no se rozan siquiera, viven vidas paralelas sin puntos de conexión entre los protagonistas de distintas realidades. Solo pisan la misma vereda o transitan por el mismo piso o la misma calle, respiran y exhalan el mismo aire. Si estas historias de vida se cruzan tal vez deriven en una tragedia o sean causa de una colisión cultural que los enfrente con violencia e intolerancia de extrañezas incompatibles de expectativas sociales y matrices culturales. Un accidente de tránsito en la vía pública, un intento de interacción entre el cuida coches y el pequeño burgués que busca estacionamiento en la disputada reserva de espacio callejera, evidencian esta brutal confrontación de historias que no tienen nada en común. Siguiendo este planteo de podemos suscribir a la idea de "las ciudades en la ciudad, laberinto de planos que se contradicen, que se empalman, que negocian, que disputan cotidianamente." (MONSIVAIS et al., 2001, p. 34)

$\mathrm{Al}$ analizar la ciudad su conformación presenta una disposición que desplaza las categorizaciones binarias de urbano /sub urbano, campo / ciudad, centro /periferia. El dibujo citadino expresa una amalgama de componentes que estructuran otra geografía. Los límites que establecían una clara diferenciación de partes (por ejemplo zonas pobladas y descampados) se desdibujan. Las fronteras entre el barrio y la ciudad se desintegran. El aumento demográfico de la ciudad, la inauguración de calles pavimentadas y la construcción de nuevas viviendas en lotes que son copados tienen un efecto en el paisaje. No solo desestructura la división del casco histórico, va más allá, la destruye. En este proceso es importante rescatar visiones que integren los paisajes con los modos de vivir y de imprimir sentidos de vidas en los territorios de la ciudad. Es decir integran la siguiente idea: "[...] la comprensión de la ciudad exige pensar juntos el espacio geométrico de los urbanistas y el antropológico de los peatones, o sea el de los que planifican y fabrican y el de los que se apropian de ella" (MONSIVAIS et al., 2001, p. 51). 
La ciudad tiene sus flujos internos, los sujetos con sus desplazamientos entran y salen de distintos casilleros de la vida social. La participación de los sujetos en la vida de la ciudad modula relaciones de todo tipo. La ciudad en la noche, durante las luces del día, en los atardeceres, propone escenas diversas. La ciudad es un desafío de estar en ella, de escaparse, no ser descubierto, conquistarla, ganarla, gozarla, vivirla, sufrirla y padecerla. La ciudad arropa lazos afectivos con escuelas, filiaciones deportivas, territorialidades y el devenir de los aconteceres produce eventos emocionales de enorme vitalidad e intensidad afectiva.

La ciudad produce mitos fundacionales, imaginarios sociales, engendra sueños y fantasías hacia el destino. Este componente mágico es relevante porque a pesar de ser intangible, carecer de materialidad y ser inaprehensible desde el sentido de la visión, transmite posibles sensaciones: de hostilidad, violencia, mística, pavor según el particular intersticio del croquis urbano donde estemos localizados. La ciudad posee zonas que se cargan de significados simbólicos potentes para los sujetos. En sus entrañas se alojan tensiones históricas de luchas de poder y saber ligados a prácticas oscurantistas, hechizos, brujerías, maleficios que engendraron los "mitos más inverosímiles" (CACHORRO, 2002, p. 2).

El desmantelamiento de uno de los estadios de futbol de la ciudad de La Plata expresa miradas nostálgicas de sus fieles adherentes. Las epopeyas heroicas construidas en la gramilla verde de 1 y 57 hacen rememorar sonidos y ecos que retumban en las cabezas encantadas de los tibios simpatizantes albirrojos. Muchos se llevan un trozo de tablón y lo guardan celosamente como un pedazo de historia y hasta compran o reservan una tira completa de plateas obsoletas para exponer con orgullo en la calidez de un hogar platense. Siguiendo a Le Goff (1991, p. 227) se constituye en "materiales de la memoria colectiva y de la historia". La posibilidad de habitar otro estadio se acompaña de creencias paganas, intrusión de cábalas, atribuciones de suertes divinas que protegen los resultados deportivos. 
La ciudad es resignificada en los nuevos recorridos y las moradas de los fines de semana en los espectáculos deportivos con una mudanza hacia el estadio único de la ciudad de la Plata.

La elaboración reflexiva de otro grupo de fervientes "hinchas" de Gimnasia y Esgrima de La Plata se movilizan con una eterna e incorruptible fidelidad institucional, haciendo uso de dispositivos de queja, asentadas y manifestaciones colectivas para la conservación de un territorio como residencia fija y la negación de una posible mudanza a otro sitio de la ciudad y evitar ser "desterrados en la imposición/pérdida de la localía en los partidos de fútbol" (BRANZ; BYLIK, 2007, p. 130).

La construcción de la ciudadanía se cocina en la relación del cuerpo de los sujetos con la ciudad. La afección es mutua. El paisaje de la ciudad reformulado con la inauguración de circuitos aeróbicos, rampas para discapacitados motores, dragados de lagos, remodelación de plazas, forestaciones de calles, instalación de juegos para niños, en su conjunto modifican la fisonomía y las posibilidades de desplazamiento e interacción entre sus habitantes. El planteo táctico de la ciudad propicia en algunos casos la circulación sin estancia prolongada en un sitio o puede armar un lugar disfrutable en la quietud de un lapso de tiempo prolongado en un espacio verde y con ello asegurar relaciones humanas que pongan cara a cara a sus ciudadanos.

En este proceso de hacer uso de los derechos de ciudadano se manifiestan luchas de poder en un contexto de historias con expectativas sociales diferentes. En el Teatro Argentino de la Ciudad de la Plata se ofrecen espectáculos cuya agenda cultural seduce a quienes gustan del ballet, la opera, las muestras de obras de arte. En las adyacencias del edificio, sus pasillos escalinatas, patios internos seducen a los jóvenes del skate para desplegar sus destrezas en una disposición irregular de desniveles de cemento. La confrontación de vocaciones existenciales disimiles es un conflicto mediado por las autoridades de la Municipalidad que sugieren reubicar a los jóvenes en la plaza Belgrano entregándoles un espacio diseñado por arquitectos especializados en la construcción de rampas para 
promocionar estas prácticas corporales. Otro proceso interesante es el de la emergencia y proliferación de las prácticas corporales del parkour en la ciudad reseñados por Cesaro, Villagran y Scarnatto (2009, p. 9) con el despliegue de motricidades inéditas haciendo uso de técnicas de saltos, giros y trepadas en las posibilidades urbanas que les ofrecen los paisajes platenses (edificios, escalinatas, grutas del bosque, etc.). El deseo de explorar, inventar y socializar estas destrezas corporales constituye una excusa excelente para construir redes de relaciones sociales entre jóvenes.

La trama fina de las relaciones humanas que se entablan en la construcción de territorios por hacer habitables cada parcela de la ciudad, nos hace ver que la geografía urbana resulta parcial e incompleta entenderla desde su métrica o sus dimensiones abstractas esbozadas en un plano topográfico. Siguiendo esta perspectiva podemos anteponer la topología a la topografía cuando el autor nos señala:

La topología se ciñe al espacio, de otra forma y mejor. Para ello utiliza lo cerrado (dentro), lo abierto (fuera), los intervalos (entre), la orientación y la dirección (hacia, delante, detrás), la cercanía y adherencia (cerca, sobre, contra, cabe, adyacente) la inmersión (en) ... los lugares como tales, contenidos y continentes, definidos, delimitados, recortados, es decir métricos o mensurables, sino relaciones de vecindad, de proximidad, de alejamiento, de adherencia o de acumulación, es decir entre las posiciones. El estar ahí y sus relaciones con el exterior. La topología es la base de la topografía de los mapas y los planos. (SERRES, 1995, p. 68).

\subsection{VIDA COTIDIANA}

La ciudad cobra sentido a partir de las prácticas desplegadas por los ciudadanos en la vida cotidiana. La ciudad tiene una vida cotidiana. Es decir la vida con rutinas, regularidades, orden cíclico de actividades, tareas y operaciones de los sujetos en la ciudad. La vida cotidiana esta asumida como evidente y se impone como lo 
obvio y natural, no se la suele cuestionar, se practica en forma acrítica. La vida cotidiana es importante para entregar a los sujetos certezas y seguridades existenciales en los ritmos monótonos y previsibles del día a día. En el modo de contemplar este concepto "la vida cotidiana se organiza alrededor del aquí de mi cuerpo y el ahora de mi presente" (BERGER; LUCKMAN, 1997, p. 39) y por otra parte se presenta como algo coherente, real e incuestionable que cae por su peso desde la acción interpretativa de los sujetos. Esta incorporación de la realidad se basa en la aprehensión no problemática de un mundo que se descubre y que precede a la aparición del ser humano. El sujeto se inscribe en una trama intersubjetiva que está al alcance de la manipulación corporal.

La revolución de la vida cotidiana, alterar los circuitos, cambiar las rutas, mudarse de un barrio a otro, dejar la escuela, perder el trabajo, abandonar un sitio de reunión social habitado con alta frecuencia y regularidad, genera profundas crisis existenciales que exigen procesos de adaptación y un reordenamiento de las series monótonas y rutinarias a las que se estaba acostumbrado. Se busca construir nuevos hábitos de vida y existen distintos niveles de plasticidad para ajustarse a este tipo de desafíos. Son procesos desestructuradores que exigen pensar desde otro lugar o inventar, descubrir con herramientas desconocidas las salidas a encrucijadas novedosas. En la incomodidad que ofrece la vida cotidiana a los sujetos existe la oportunidad de romper el orden de cosas. La "invención de lo cotidiano", que nos alienta Michelle de Certeau se especifica en los modos de hacer a través de operaciones que echan mano a técnicas, tácticas y estrategias. El autor menciona la necesidad de jugar con los "acontecimientos" para hacer de ellos "ocasiones". Hay una terrible creatividad en las prácticas cotidianas expresadas en "[...] las buenas pasadas, artes de poner en práctica jugarretas, astucias de cazadores, movilidades maniobreras, simulaciones polimorfas, hallazgos jubilosos, poéticos y guerreros." (DE CERTEAU, 1996, p. L).

La vida cotidiana tal como lo señala Norbert Lechner (1990) se opone a lo no cotidiano. En líneas generales cuando existe una 
inercia de ella y un malestar por su tediosa repetición rutinaria aparece el interés por entenderla, explicarla y problematizarla, como meta ulterior, cambiarla. En un abordaje conceptual la vida cotidiana es algo obvio, natural y evidente. Por tener estos rasgos no se la cuestiona y mantiene su persistencia reiterativa. La vida cotidiana entonces puede ser estudiada intentando hacer visible los aspectos estructurales que la constituyen. En esa tarea proponemos cuestionar el sentido común, aquellos criterios de normalidad que aceptamos como sujetos inscriptos en ordenamientos continuos del devenir. En la asunción de una postura reflexiva sobre los eventos aparentemente triviales y banales de la vida ordinaria puede trazarse la propuesta de "[...] ]enfocar lo visto pero no registrado. Transformar la perspectiva común de lo común y, como caso especial, realzar la accesibilidad estable a lo común; hacerlo visible". (LECHNER, 1990, p. 51).

En las sesiones semanales de entrenamiento en los gimnasios, las periodicidades de encuentros sexuales entre amantes, las escapadas a termas de otras ciudades, los encuentros deportivos de los fines de semana, el paseo familiar del domingo y la asistencia a espectáculos circenses callejeros hay una previsibilidad de la vida cotidiana, una relación de los sujetos con los laberintos de la ciudad que puede ser sometido a procesos de objetivación. En este marco rescatamos que:

$$
\begin{aligned}
& \text { [...] las rutinas cotidianas con su casi constantes } \\
& \text { interacciones con los demás, estructuran y } \\
& \text { conforman lo que hacemos [...] el estudio de la vida } \\
& \text { cotidiana nos revela de que manera actuamos los } \\
& \text { seres humanos de forma creativa para conformar la } \\
& \text { realidad [...] el estudio de la interacción social en la } \\
& \text { vida cotidiana arroja luz sobre instituciones y } \\
& \text { sistemas sociales más amplios. (GIDDENS, 2002, } \\
& \text { p. 122). }
\end{aligned}
$$

Desde esta manifestación de la vida cotidiana podemos potenciar nuestras lecturas interpretativas de las propuestas corporales que se presentan en la ciudad, sus sentidos y significados.

La posibilidad de ruptura existencial del ritmo previsible y monótono del día a día en la ciudad se expresa en situaciones 
extremas o imprevistos inéditos del caprichoso azar del destino. El 9 de julio de 2007 la ciudad fue afectada por una impensada nieve que cubrió toda su superficie de extensión. Este evento fuera de lo común, es una alteración drástica que más allá de generar un paisaje pintoresco, altera las subjetividades de sus habitantes. Sus mundos de vida por un breve lapso de tiempo se cambio en forma radical. El estado de ánimo viró hacia caras de asombro, alegría, risas, y movilizó la experimentación de sensaciones corporales y motrices que la generosa naturaleza desparramó por cada rincón de la ciudad. Correr en la nieve, saltar en ella, hundirse, arrojarse con bolas de nieve, hacer muñecos, sacar fotos, improvisar trineos y simular sky, probar resbalones con patines o hacer equilibrio en bicicleta en un terreno momentáneamente deslizante en extremo. En ese día memorable y atípico de La Plata, la gente inauguro y compartió otro tema de conversación, sus mediocridades costumbristas se cambiaron por un momento. La felicidad se dibujó hasta los rostros de los ciudadanos más amargos. Fue un día excepcional, es una excepción de la vida cotidiana, es algo no cotidiano.

Este ejemplo nos confirma el peso de la definición de vida cotidiana y el profundo condicionamiento, que las condiciones concretas de existencia en el hacer repetitivo y rutinario de sus cosas, le imponen a los sujetos.

[...] la vida cotidiana es la reproducción del hombre particular. Todo hombre al nacer se encuentra en un mundo ya existente, independientemente de él. El particular nace en condiciones sociales concretas, en sistemas concretos de expectativas, dentro de instituciones concretas. La reproducción del hombre particular es siempre reproducción de un hombre histórico, de un particular en un mundo concreto. (HELLER, 1987, p. 21).

La vida cotidiana expresa su anclaje en las nociones de tiempo y espacio. Es decir la cadencia, el ritmo de vida de los sujetos expresa cierta figuración. Los modos de organizar las actividades, jerarquizarlas y distribuir tiempo en la experiencia citadina es una composición original y hasta artesanal. El tiempo expresa criterios 
de organización, improvisación, planificación y tiene una lógica de composición y manifestación. El tiempo como construcción subjetiva está desplegado en territorios de acción. Los circuitos semanales, las trayectorias por el espacio público, las rutas diarias son acciones sociales, los posibles viajes y desplazamientos expresan una relación con la geografía y se articula con la historia. Milan Kundera (1995) expresaba las percepciones espaciales y temporales que vivencian en la carretera un conductor que transita por la calle disfrutando de la contemplación del paisaje con un desplazamiento lento y parsimonioso en medio de la calle que obstaculiza la vertiginosa velocidad de un auto deportivo que no encuentra el espacio de maniobra para adelantarse y rebasar al inoportuno obstáculo, en el conductor apresurado su velocidad de aceleración se aminora y desafía la paciencia.

La vida cotidiana es alterada cuando las categorías de tiempo y espacio sufren profundas transformaciones. Los procesos de "desespacialización", "descentramiento" y "desurbanización" de la ciudad, (MARTÍN BARBERO, 2004, p. 286) afectan las experiencias de los sujetos cuando comienza a prevalecer el flujo la circulación de las personas por encima de los estáticos encuentros cara a cara. Los agiles atajos, las evasiones de grupos, el abandono de sitios de reunión social donde se tejen las relaciones y vínculos entre ciudadanos comienzan a modelar otros modos existenciales de estructurar las vidas cotidianas, de una manera más descorporeizada.

Este cambio profundo y estructural inaugura otros modos de constitución de los sujetos a través de tramas vinculares inéditas, con soportes de comunicación despersonalizados que se intercalan con las formas de interacción más tradicionales. La construcción de la persona como nos señalaba la minuciosa descripción de la microsociología, en esa "presencia mutua continua entre individuos en los encuentros cara a cara" (GOFFMAN, 1994, p. 27) que aseguraban la internalización de roles en encuadres especificados, dramaturgias en distintos escenarios de la vida social, dejan de ser formas excluyentes de producción de sujetos en la vida cotidiana. 


\subsection{Cuerpo}

En la ciudad y sus ritmos de vida cotidiana se pone el cuerpo, los ciudadanos lo arriesgan, lo muestran, seducen, pelean, habitan con él, en distintos espacios de la ciudad. Poner el cuerpo en la calle para participar de una congregación colectiva en reclamo de algo, desplegar prácticas corporales en recintos cerrados (gimnasios, clubes, spas, natatorios, centros de educación física). Ocupar los espacios verdes para correr en los parques, caminar por el bosque, apropiarse de los juegos municipales, saltar con las patinetas, recorrer las calles en rollers, o en bicicleta, bailar tango, hacer ruido al compás de los tambores, las comparsas, murgas y candombes. Podemos ver los cuerpos de los ciudadanos moviéndose en cada rincón de la ciudad. Ver las propuestas clandestinas de travestis, prostitutas en esquinas rojas de la ciudad en distintas horas del día, divisar el amontonamiento de jóvenes en una esquina predilecta del casco urbano o los malabares en las esquinas, los ensayos de coreografías corporales en glorietas, anfiteatros del bosque.

El cuerpo de los sujetos necesita sitios donde encontrarse a salvo, donde vibrar, gozar, pecar, sentir. Un observador puede registrar el uso del espacio público en la intersección de las calles 7 y 50 para los festejos deportivos de los equipos de la ciudad. La sensibilidad corporal está construida en opciones biográficas diversas. El cuerpo exterioriza el miedo, la paranoia de la violencia urbana, está alerta, intenta cuidarse.

Los malabares en las calles, contienen un sentido que, lejos está de ser una rápida expresión corporal de juglares urbanos. No es arte callejero. Es el desesperado cuentapropismo de sujetos que encuentran esta manera de generar humildes recaudaciones. En la forzada cara de alegría que nos ofrece el precario acróbata en las esquinas, se manifiesta la realidad cruda de personas que viven al día al ritmo de las fases de los semáforos. El sentido de pobreza y el montaje de estrategias de supervivencia poniendo el cuerpo en la ciudad, para que esta sea generosa y tenga piedad ante tanta miseria" (CACHORRO, 2009, p. 5) 
Al momento de pensar aportes desde el campo del cuerpo y la cultura en construcción de la ciudadanía, entendemos necesario definir el cuerpo humano en diversos planos. El cuerpo es la constancia material, la evidencia física tangible de la persona. Hasta allí podemos apreciar esa superficie con volumen tridimensional posible de ser nombrado con el concepto corporeidad. Solo hasta ahí es válida esta categoría conceptual. La corporeidad como constancia y evidencia de un soma ocupando un sitio en el espacio no guarda diferencias sustanciales entre animales y seres humanos. El cuerpo en su contundencia real, concreta al momento de ser atravesado por el lenguaje o por las prácticas culturales deja de ser corporeidad para convertirse en corporalidad.

La corporalidad podemos entenderla como una diferencia categórica entre el mundo animal y el mundo humano. La corporalidad se localiza en las producciones de múltiples significados sociales incrustados en los cuerpos. El resultado de esta reflexión fenomenológica es abierto, desencadena invención de gestualidades, motricidades, patrones del movimiento, técnicas corporales de la vida pública, lógicas complejas del erotismo y la sexualidad. Si comparamos la plasticidad y la condición fluida y con formas cambiantes que puede adoptar el cuerpo en distintas civilizaciones, en las formas corporales nos daremos cuenta de la distancia abismal que este concepto exclusivo de los sujetos sociales se distancia de la corporeidad que a lo sumo puede asumirse como una realidad somática sujeta a mecanismos anatómicos y fisiológicos que demuestran su estado de vida vegetativa. La corporeidad activa conductas mecánicas, el concepto está más cerca del instinto o los impulsos reflejos. Radica en los comportamientos sin mediación de los mandatos institucionales ni los ordenamientos simbólicos, los diques de los interdictos o los tabúes morales y éticos de las buenas y esperables formas de desenvolverse con el gran otro interpelador.

La perspectiva teórica desde donde se enfoca al cuerpo humano puede ser analizada identificando planos tal como explica y 
fundamenta José Alberto Mainetti (1972, p. 150) al organizar las siguientes reflexiones en torno a la filosofía del cuerpo: Ontofanía, Fenomenología y Metafísica.

Realidad, fenómeno y misterio del cuerpo humano, según las respectivas relaciones de alteridad, identidad y transitividad que mantiene el yo con su cuerpo (yo tengo, yo soy yo existo mi cuerpo). Corporeidad, corporalidad y encarnación, según se vea el cuerpo como sustancia, sujeto o existencia (tesis dualista, fenomenológica o existencial). Cuerpo conocido, vivido y pensado, según los tres grados de saber en que el cuerpo trasciende a si mismo (conocimiento, contemplación y pensar).

Este criterio de organización del cuerpo es fundamental para establecer y explicitar posiciones teóricas para hacer planteos en el tema. La parte que nos interesa estudiar es la del cuerpo como construcción social porque

[...] sobre esta materialidad común de los cuerpos, la vida sociocultural construye prácticas disimiles (técnicas corporales cotidianas, modos perceptivos, formas de habitar el espacio, gestos, expresiones de la emoción, síntomas, danzas) y da lugar a representaciones de la corporalidad y de sus vínculos con el mundo también diferentes. El cuerpo inevitablemente es atravesado por los significantes culturales y el mismo se construye en un particular productor de significantes de la vida social. La reflexión antropológica sobre la corporalidad, desde Marcel Mauss en adelante, ha dirigido su atención a develar el carácter culturalmente construido de la misma" (CITRÓ, 2009, p. 39).

La explicitación del punto de vista teórico desde donde hablamos, nos lleva a capturar la complejidad de la corporalidad y dimensionar sus problemáticas. Ello implica bucear en otros modos de acercamientos al cuerpo humano. Si planteamos la corporalidad de los ciudadanos en la vida cotidiana son infinitas las posibilidades de lectura, habilita una hermenéutica del cuerpo más seductora o entretenida. No es una trivialidad una propuesta corporal atractiva, 
ese componente seductor (traducido como "llevar consigo") es indispensable para consolidar compromisos corporales de los ciudadanos a partir del deseo de estar embarcado con una aventura corporal que provoque, inquiete, incomode y mantenga enganchado al sujeto. La comprensión de las vocaciones corporales y motrices de los ciudadanos, están delante de la imposición de nuestros intereses curriculares, que si bien pueden tener una impecable resolución técnica, no pueden elaborarse en el caprichoso autismo solipsista. Si no se traducen las tendencias corporales, sus contextos de producción y emergencia cultural, corremos el riesgo de ser extemporáneos y caer con propuestas corporales estériles o inocuas a las inquietudes de los demás.

El ejercicio de otro tratamiento y lectura del cuerpo puede efectuarse echando mano al mundo imaginario y simbólico que los sujetos construyen en sus recorridos biográficos. El cuerpo en la perspectiva está ligado a una "experiencia que siempre se renueva" resaltando la importancia de construir el saber que los sujetos descubren en la vivencia cotidiana de sus "[...] asuntos, molestias, necesidades, impedimentos; sus regularidades y trastornos; sus digestiones, reglas y detalles sucios del amor [...]" (ROVALETTI, 1998, p. 366) desprendiendo de esta contemplación una puerta de acceso exclusiva: la propia vida con un carácter inacabado e incompleto.

Abordar el carácter dinámico y creativo de los cuerpos humanos en el protagonismo de la cultura es una labor de invención artesanal que opera recuperando piezas, armando sus posibles relaciones capaces de decodificas y traducir los sentidos sociales que en ellos se ponen en juego. Ir en busca de sentidos construidos y negociados por los cuerpos habilita la apertura a una subjetividad sensible y vulnerable a la alteridad ajena al observador. En vez de "escribir la historia de uno en el cuerpo del otro", (DE CERTEAU, 1993, p. 11) es aconsejable abrirse a la alteridad. El autor nos enseñaba con esta oración a evitar las imposiciones teóricas forzadas, podemos correr una aventura exploratoria capaz de descubrir al otro y en el mismo movimiento descubrirnos a nosotros mismos en una actitud despojada 
de convencionalismos y clasificaciones taxativas que cercenan la posibilidad de reempadronar, reclasificar las propias categorizaciones en forma libre y crítica autogestiva.

La matrices de formación docente en el campo de la Educación Física disponibles para hacer lecturas o ver el cuerpo hacen prevalecer enfoques psicomotriz, físicodeportivo, pedagógico, especulativo. Se derivan de estos abordajes la prevalencia de materiales acerca de la biomecánica, disciplina corporal, entrenamiento de las capacidades motoras, fisiología del ejercicio, técnicas de rehabilitación física, sistemas de juego y deportes, estructuras de clases, didácticas de lo corporal. Estos criterios de interpretación pueden ser relativizados y suspendidos para abrirse a la aparición de otros sentidos corporales y aprovechar las emergencias corporales para brindar otras explicaciones de los fenómenos deportivos, lúdicos, recreativos, como elementos de la vida social. Las intenciones de búsqueda y exploración se inscriben en el encuentro con explicaciones socioculturales de las figuraciones del cuerpo en la ciudad capaces de generar insumos diferentes al apelar a otras teorías y autores que analizan el cuerpo desde tratamientos alternativos.

Los lineamientos curriculares esbozados en el área Educación Física de la Provincia de Buenos Aires (DIRECCIÓN..., 2008, p. 26) al plantear los tratamientos sobre el cuerpo, ponen énfasis en el trazado los siguientes ejes: la corporeidad y la motricidad humana (constitución corporal, conciencia corporal y habilidades motoras), corporeidad y sociomotricidad (la construcción del juego deportivo y el deporte escolar), corporeidad y motricidad en relación con el ambiente (relación con el ambiente, la vida cotidiana en ámbitos naturales, las acciones motrices en la naturaleza). Las consecuencias de esta elección derivan en una proyección del cuerpo de los aprendices, circunscripta a aspectos que hacen prevalecer el dominio de una dimensión físico motriz que proyecta en los sujetos la construcción de una disponibilidad motriz. El aporte a la construcción de la ciudadanía estaría presentado desde el trabajo hecho sobre los aprendizajes motores y su efecto en el desenvolvimiento de alumnos seguros y experimentados de sus cuerpos. Creemos valiosa la 
apertura de espacios para la vivencia y el protagonismo de los cuerpos para el enriquecimiento del patrimonio corporal y motriz, las seguridades corporales, el dominio técnico de un amplio espectro de deportes o la participación colectiva en propuestas de campamento, colonias de vacaciones o torneos.

La perspectiva puede ser enriquecida aún más, si se piensan las relaciones del cuerpo, la ciudad, los sujetos y las vidas cotidianas desde la perspectiva de la corporalidad y la cultura. La recuperación de estos andamiajes teóricos pueden potenciar la relevancia social en la educación corporal que no se ciñe solamente a aspectos disciplinares de un área curricular, obliga a pensar en aperturas, diagonales, en miradas complejas multidisciplinarias capaces de articular saberes de otras procedencias, por ejemplo la comunicación corporal, la antropología de las emociones, la sociología del deporte, las historias de los juegos tradicionales, para redimensionar la construcción de los cuerpos en el mismo momento que acompañamos el proceso de construcción de la ciudadanía.

Si hacemos un desplazamiento de la mirada hacia otros aspectos, podemos establecer relaciones entre el cuerpo y la ciudad. En las conexiones de estos conceptos se hallan otro tipo de problemas y temas de interés. Las textualizaciones posibles de producir desde este abordaje, nos conducen a otros planteos y teorizaciones. Las técnicas corporales, los movimientos humanos y artificiales, las motricidades, las biomecánicas no surgen en el vacio ni tampoco se expresan como acciones motrices universales ahistóricas. Los cuerpos están regulados, afectados por las propiedades específicas de las ciudades. Las configuraciones del cuerpo, las prácticas corporales adquieren sentido en un aquí y ahora coyuntural.

La palabra moderna gimnasio procede de gymnoi en griego, que significaba desnudos... era en el gimnasio donde el joven aprendía que su cuerpo era parte de una colectividad más amplia llamada polis, que el cuerpo pertenecía a la ciudad...en el gimnasio el muchacho aprendía cómo utilizar su cuerpo de manera que pudiera desear y ser deseado de manera honrosa. (SENETT, 2007, p. 47) 
Nos señalaba con muchísima claridad las estrechas relaciones que mantienen a lo largo la historia de distintas civilizaciones los cuerpos humanos con las ciudades. Sus influencias recíprocas materializadas en objetos materiales o criterios de composición de flujos vehiculares, circulación por arterias obturadas, entre otras estructuras análogas de interpretación. De igual manera en sentido del gimnasio y su significado ocupa un lugar estratégico en la ciudad y está pesado para educar el cuerpo de los jóvenes para que sepan desenvolverse con competencia en las actividades de ciudadano.

El gimnasio en el curso de la historia ha sido resignificado constantemente. A la lectura lineal del posible catálogo de actividades corporales a la carta que ofrecen estas agencias para el cuerpo de los ciudadanos, puede interrogárseles los modos de apropiación, de uso, que los practicantes construyen con estas organizaciones. Las socialidades, subjetividades, intersubjetividades, imaginarios, representaciones que le dan vida y sostienen su posibilidad de continuar, ser y estar o su decisión de cerrar el establecimiento.

Un plano de la lectura a atender para integrar a las interpretaciones de sentido del cuerpo radican por ejemplo en las confianzas, los deseos, las motivaciones puestas en juego durante las performances corporales. "Las configuraciones sociales duraderas, como hilos invisibles que atan y desatan los individuos entre sí" (SIMMEL, 2002, p. 16) al hacer abordajes sociológicos construye otro tipo de objetos de estudio "la amistad, el amor, el secreto, la amistad, los encantos de objetos como el perfume", que pueden orientarnos en nuestra travesía de redescubrir el cuerpo acuñando otro tipo de categorizaciones conceptuales, desde otros ángulos de la mirada.

\section{Conclusiones}

En lo concerniente al concepto ciudad, podemos certificar la existencia de distintos marcos teóricos que abordan como tema desde distintas disciplinas sociales. Los mapas y cartografías de la ciudad nos ofrecen herramientas teórico metodológicas importantes para 
aprovechar el listado de prácticas corporales existentes en la ciudad de La Plata y traducir en ellos los sentidos sociales que le imprimen los ciudadanos embarcados en alguna de sus propuestas corporales disponibles en la oferta. La ciudad expresa en sus entrañas revoluciones, cambios, desplazamientos y provoca la capacidad de contemplación del investigador para capturar los procesos emergentes materializados en las prácticas corporales.

Con respecto a la construcción lingüística vida cotidiana, descubrimos un concepto clave para entender el pulso de la ciudad, los ritmos de la temporalidad, los modos de estructurar los trayectos por el espacio, la forma se hacerse ciudadano apropiándose de las tramas intersubjetivas ancladas en coordenadas específicas y situacionales. Nos ofrece un lente interpretativo sobre aquellas rutinas, regularidades, monotonías, rupturas, discontinuidades en los ciclos de vida diarios experimentados por los sujetos, donde el cuerpo está involucrado. Nos avisa de la importancia de no dar por obvio, natural y evidente las monotonías costumbristas de las vidas ordinarias.

Por último, el uso de la palabra cuerpo, alienta una revisión ineludible de los presupuestos teóricos que lo expresan a través de constructos conceptuales tales como corporalidad y corporeidad. Los tópicos enunciados, poseen influencias de distintas campos disciplinares. La convergencia de distintos tratamientos del concepto cuerpo, produce amalgamas epistémicas de distinto tipo, atribuye una diversidad de significados a términos según los contextos particulares de producción. La revisión de estos materiales abstractos nos obliga a ponerlos en diálogo con las realidades estudiadas, medir su pertinencia y correspondencia con los procesos de manifestación de la cultura corporal en las ciudades. 
City, body and daily life. Theoretical material of the research in the city of La Plata

Abstract: This work is part of the research project "The field of body practices in the city of La Plata" and proposes the composition of a narrative of the terms city, body and daily life, from a theoretical construction by establishing links with empirical material collected in field work, which relieved social gathering places that offer tangible proposals. The terms are interrelated, are key gateways to understand the ways of building citizenship in the city of La Plata, with attention to the specifics of social production to display subjects in their tasks, activities and bodily practices.

Keywords: Citizenship, proposals practices, body practices.

Cidade, corpo e vida cotidiana. Materiais teóricos de uma investgação na cidade de La Plata

Resumo: Este trabalho se enquadra no projecto de investigação "O campo das práticas corporais na cidade de La Plata ". Propõe a composição de um texto descritivo dos termos cidade, corpo e vida cotidiana, desde uma perspectiva de construção teórica estabelecendo laços com materiais empíricos coletados no trabalho de campo, onde se revelaram lugares de reunião social que oferecem propostas corporais. Os termos estão relacionados entre si, são portas de acesso fundamentais para compreender os modos de construir a cidadania na cidade de La Plata, salientando os traços específicos de produção do fazer social em que atuam os sujeitos, suas tarefas, atividades e práticas corporais.

Palavras chave: Cidadania, propostas corporais, práticas corporais. 


\section{REFERÊNCIAS}

BERGER, Peter; LUCKMAN, Thomas. La construcción social de la realidad. Buenos Aires: Amorrortu. 1997.

BRANZ, Juan; BILYK Pablo. Del Bosque no me voy. Fútbol e Identidad. Los Hinchas de Gimnasia que resisten al cambio de su Estadio. Tesis de grado Licenciatura en Comunicación Social. La Plata: Facultad de Periodismo y Comunicación Social. Universidad Nacional de La Plata. 2007.

CACHORRO, Gabriel Armando. Proyecto de investigación El campo de las prácticas corporales en la ciudad de La Plata. Programa de Incentivos a la Investigación de FHCE. UNLP: La Plata, 2007. Disponible en: < http:// www. fahce.unlp.edu.ar/investigacion/proyectos-de-investigacion/ elcampodelasprcticascorporales enlaciudaddelaplata/>. Acceso en: 07 jun. 2009.

CACHORRO, Gabriel. El fútbol y los de la rambla. Continuidades y rupturas con el fútbol y los chavos banda. Revista Digital - Buenos Aires, v. 8, n. 55, dic. 2002. Disponible en http://www.efdeportes.com/. Acceso en: 07 feb. 2010.

CACHORRO, Gabriel. Prácticas corporales. Traducción de sentidos en la ciudad. Revista Pensar a prática, Goiania, v. 12, n. 2, ago. 2009. Disponible en: <http:// www.revistas.ufg.br/index.php/fef/rt/captureCite/6326/4966>. Acceso en: 26 ago.2010.

CALVINO, Italo. Ciudades invisibles. Madrid: Siruela, 1999. (Colección Millenium)

CESARO, Roman; SCARNATTO, Martín; VILLAGRÁN, Juan Pablo. La ciudad y los cuerpos. Prácticas, movimientos y nuevas performances. ENCUENTRO INTERNACIONAL DE JUVENTUD Y MEDIOS DE COMUNICACIÓN E INDUSTRIAS CULTURALES. 1, 2009. Actas....La Plata: Facultad de Periodismo y Comunicación Social, Universidad Nacional de La Plata. 2009.

CITRÓ, Silvia. Cuerpos significantes: Travesías de una etnografía dialéctica. Buenos Aires: Biblos, 2009.

DE CERTEAU, Michel. La Escritura de la historia. Distrito Federal: Universidad Iberoamericana. 1993.

DE CERTEAU, Michel. La invención de lo cotidiano. 1 Artes de hacer. Distrito Federal: Universidad Iberoamericana. 1996.

DE CERTEAU, Michel.; GIARD, Luce; MAYOL, Pierre. La invención de lo cotidiano: 2 habitar, cocinar. Distrito Federal: Universidad Iberoamericana, 1999.

DIRECCIÓN GENERAL DE CULTURA Y EDUCACIÓN. Diseño curricular para la Educación Secundaria $2^{\circ}$ año Secundaria Básica. Educación Física. La Plata: 2008.

GIDDENS, Anthony. Sociología. Buenos Aires: Alianza, 2002. 
GOFFMAN, Erving. La presentación de la persona en la vida cotidiana. Buenos Aires: Amorrortu, 1994.

HELLER, Agnes. Sociología de la vida cotidiana. Barcelona: Península, 1987.

KUNDERA, Milan. La lentitud. Barcelona: Tusquets, 1995.

LECHNER, Norbert. Los patios interiores de la democracia: Subjetividad y política. Santiago de Chile: Flacso, Fondo de Cultura Económica, 1990.

LE GOFF, Jacques. El orden de la memoria. El tiempo como imaginario. Barcelona: Paidos. 1991.

MAINETTI, José Alberto. Realidad, Fenómeno y Misterio del cuerpo humano. La Plata: Quiron, 1972.

MARTIN BARBERO, Jesús. El oficio de cartógrafo: Travesías latinoamericanas de la comunicación en la cultura. Buenos Aires: Fondo Cultura Económica, 2004.

MONSIVAIS, Carlos; MARTÍN BARBERO, Jesús; REGUILLO, Rossana. El laberinto, el conjuro y la ventana: Itinerarios para salir de la ciudad. Jalisco: Iteso, 2001.

ROVALETTI, Lucrecia. Corporalidad: La problemática del cuerpo en el pensamiento actual. Buenos Aires: Lugar, 1998.

SENETT, Richard. Carne y piedra: El cuerpo y la ciudad en la civilización occidental. Madrid: Alianza, 2007.

SERRES, Michel. Atlas. Madrid: Cátedra, 1995. (Colección Teorema)

SIMMEL, George. Cuestiones de sociología, Barcelona: Gedisa, 2002.

WILLIAMS, Raymond. Palabras claves: el vocabulario de la cultura y la sociedad. Buenos Aires: Nueva Visión, 2003.

Endereço para correspondência

Gabriel Armando Cachorro 68

N. 2205 e/139 y 140

La Plata CP 1900 Buenos Aires - Argentina

Recebido em: 26.08.2010

Aprovado em: 17.10.2011

Movimento, Porto Alegre, v. 17, n. 04, p. 225-246, out/dez de 2011. 
